Check for updates

Cite this: RSC Adv., 2018, 8, 36754

Received 29th August 2018

Accepted 3rd October 2018

DOI: $10.1039 / c 8 r a 07216 g$

rsc.li/rsc-advances

\section{Alkaline treatment of used carbon-brush anodes for restoring power generation of microbial fuel cells $\dagger$}

\begin{abstract}
Lin Li, Bo Jiang, (D) Dawei Tang, ${ }^{*}$ Xiaoliang Zhang, Kunpeng Yuan and Qian Zhang
Long-term operation of microbial fuel cells (MFCs) results in an electrochemical activity decline by the degradation of the anodic biofilm. In this work, an alkaline soaking treatment is proposed as an efficient and simple method for anode regeneration. The alkaline treatment was employed in a used carbonbrush anode, and its performance was compared with those of two other traditional treatment methods, i.e. air drying and carbonization. Among all the treated MFC anodes, the one treated by alkaline soaking exhibited the highest recovery rate. A series of tests including a start-up process, scanning electron microscopy (SEM), X-ray photoelectron spectroscopy (XPS), cyclic voltammetry (CV), electrochemical impedance spectroscopy (EIS) and MFC performance were performed. The results show that alkaline soaking can modify the carbon fiber by introducing carboxyl groups onto the carbon surface and completely remove the aged biofilm, demonstrating that the alkaline treatment of used anodes is a practically effective method for the performance recovery of MFCs.
\end{abstract}

\section{Introduction}

Over the past decades, research on microbial fuel cells (MFCs) has attracted wide attention for its unique advantages to degrade organic matter in wastewater and simultaneously produce electricity by the electrochemically active bacteria (EAB). ${ }^{1-3}$ However, the power output of MFCs is still limited. The anode is a critical component of MFCs, a serves as a matrix of bacterial immobilization and a place of bioelectrochemical reaction. ${ }^{1,4,5}$ Among previously reported anode materials for MFCs, carbon-brush with a high specific surface area, low electrode resistance and strong biocompatibility has been considered as one of the most suitable electrodes for simultaneous power generation and wastewater treatment. ${ }^{3,6,7}$ The carbon-brush electrode was firstly used as an anode material in a single-chamber MFC, which achieved a high power-density of $73 \mathrm{~W} \mathrm{~m} \mathrm{~m}^{-3} .{ }^{8}$ A 90 liter MFC stack by linking individual carbonbrush anodes in series produces enough energy to power a pumping system. ${ }^{9}$ When an MFC equipped with carbon-brush anodes is fed with wastewater, a high chemical oxygen demand (COD) removal efficiency is observed. ${ }^{10,11}$ Therefore, carbonbrush anodes exhibit attractive advantages in practical sewage treatment systems due to their high power-output and COD removal.

Key Laboratory of Ocean Energy Utilization and Energy Conservation of Ministry of Education, Dalian University of Technology, Dalian 116024, China. E-mail: dwtang@dlut.edu.cn

$\dagger$ Electronic supplementary information (ESI) available. See DOI: 10.1039/c8ra07216g
Unfortunately, during the long-term operation of MFCs, the degradation of the anodic biofilm leads to a decrease of its electrochemical activity. ${ }^{12}$ More importantly, inside a carbonbrush anode, a naturally metabolism-induced aged or dead biofilm is difficult to discharge, thereby increasing the transfer resistance of substrates between the interior space of the anode and the bulk solution, and further impairing the performance of MFCs. ${ }^{13}$ This fact may lead to the decline in electric energy recuperation of an individual MFC. What's worse, in MFC stacks, if the oxidation current of MFC with the degraded anodes could not satisfy the needs of the higher uniform current from other MFCs, voltage reversal will occur and seriously limit energy recovery of MFC stacks. In this case, a number of deteriorated anodes need to be replaced, resulting in relatively high costs. Therefore, a cost-effective method for restoring power generation of used anodes is highly desired.

In recent years, some methods have been proposed to detach biofilm from the anode surface and achieve the performance recovery, like high shear stress. ${ }^{14-16}$ However, such physical method could only exfoliate parts of the biofilm and the remaining biofilm would hinder the formation of fresh biofilm. High-temperature carbonization technology is an effective strategy to decompose protein-rich biomass, e.g., such as microalgae, macroalgae and biofilm, thus removing the biofilm. ${ }^{17}$ Yang et al. ${ }^{18}$ reported that the total mass loss of the marine microalgae is more than $80 \%$ during the pyrolysis process because of the degradation of crude protein. Thermogravimetric analysis shows that the main weight loss of the marine macroalgae is attributed to the decomposition of the protein and carbohydrate content. ${ }^{19}$ However, the carbonization 
treatment of the used anodes causes the weak electrochemical activity of biofilm and the reduction of MFC performance recovery, leading to an infeasible operation in practice.

Complete removal of the aged biofilm is a crucial step towards the regrowth of electrochemically activated biofilm, which determines the recovery of the used anode capacity. In some food processing plants, the biofilm attached on plastic media is thoroughly detached by soaking it in extreme $\mathrm{pH}$ conditions, suggesting that the treatment of extreme $\mathrm{pH}$ solution may be an effective way to eliminate the aged biofilm on the substrate. $^{20,21}$ In line with this idea, this work proposes an alkaline treatment method of the MFC anode regeneration by soaking the used carbon-brush in alkaline solution. The used carbon-brush anodes are treated by three different ways including air drying, high-temperature carbonization and alkaline soaking to highlight the advantage of the alkaline treatment method. A series of tests including start-up process, scanning electron microscopy (SEM), X-ray photoelectron spectroscopy (XPS), cyclic voltammogram (CV), electrochemical impedance spectroscopy (EIS) and MFC performance are conducted to study the mechanism of alkaline treatment on the anode. The proposed alkaline treatment is expected to be a simple and effective method to restore power generation of used MFCs in practical applications.

\section{Experimental}

\subsection{Anode treatments}

A carbon-brush with $3.0 \mathrm{~cm}$ in outer diameter and $4.0 \mathrm{~cm}$ in length was used as anode. All carbon-brushes were firstly cleaned by soaking them in acetone for twenty-four $h$ and then rinsed in distilled water for three times. After the successful start-up of four MFCs with the cleaned carbon-brush anodes, three individual mature anodes of MFCs were operated with different treatment methods. The MFCs with used anodes treated by air drying, carbonization and alkaline soaking were labelled as MFC-D, MFC-C and MFC-A, respectively. Air drying was conducted by airing the mature anode in an oxygen-rich environmental chamber at $40{ }^{\circ} \mathrm{C}$ for ten days. Carbonization of the mature anode was performed in a high temperature furnace (JQF1100-30, China) under nitrogen atmosphere. After it was heated up to $300{ }^{\circ} \mathrm{C}$ at a rate of $5{ }^{\circ} \mathrm{C} \mathrm{min}{ }^{-1}$, the mature anode was then heated up to $900{ }^{\circ} \mathrm{C}$ at a rate of $10^{\circ} \mathrm{C} \mathrm{min}$ min $^{-1}$ and annealed for two hours. After heat-treatment, carbon-brush was cooled down to a temperature of $100{ }^{\circ} \mathrm{C}$ under nitrogen atmosphere. Alkaline treatment was carried out by immersing the mature anode in $\mathrm{NaOH}(1 \mathrm{M})$ solution for twelve h, washing in deionized water, and then air drying the electrode at room temperature for at least twenty-four $h$.

\subsection{MFC configuration and operation}

Four identical dual-chamber MFCs were fabricated with plexiglas plates. Each MFC consisted of an anode chamber $(3.0 \times 4.0$ $\times 7.5 \mathrm{~cm})$ and a cathode chamber $(3.0 \times 5.0 \times 7.5 \mathrm{~cm})$, which were separated by a cation exchange membrane (CEM, CMI7000, Membrane International, USA). Carbon cloth (E-TEK, B-
1A, USA) with a projected surface area of $10 \mathrm{~cm}^{2}(2.0 \times 5.0$ $\mathrm{cm})$ was employed as a cathode electrode. Effluent from an active acetate-fed MFC running for over two years was selected as the inoculum for the tested MFCs. The anolyte was composed of $0.68 \mathrm{~g} \mathrm{~L}^{-1}$ sodium acetate, $3.0 \mathrm{~g} \mathrm{~L}^{-1} \mathrm{KH}_{2} \mathrm{PO}_{4}$, $6.0 \mathrm{~g} \mathrm{~L}^{-1} \mathrm{Na}_{2} \mathrm{HPO}_{4}, 0.5 \mathrm{~g} \mathrm{~L}^{-1} \mathrm{NaCl}, 0.1 \mathrm{~g} \mathrm{~L}^{-1} \mathrm{NH}_{4} \mathrm{Cl}, 0.1 \mathrm{~g} \mathrm{~L}^{-1}$ $\mathrm{MgSO}_{4} \cdot 7 \mathrm{H}_{2} \mathrm{O}, 15.0 \mathrm{mg} \mathrm{L}{ }^{-1} \mathrm{CaCl}_{2} \cdot 2 \mathrm{H}_{2} \mathrm{O}$ and $1.0 \mathrm{~mL} \mathrm{~L}^{-1}$ trace elements solution, on the MFC performance. Both the anolyte and catholyte were pumped at $1.5 \mathrm{~mL} \mathrm{~min}^{-1}$ with continuous flow. All MFCs were operated with an external resistance at 100 $\Omega$ and a temperature of $30 \pm 1{ }^{\circ} \mathrm{C}$.

\subsection{Analysis method}

After the different treatments of used carbon-brush anodes, the surface morphology was analysed by a SEM (VEGA3, TESCAN, Czech). XPS (XSAM800, Kratos Co., UK) was employed to analyse the composition of elements on the used carbon-brush surface. CV and EIS tests were performed with a Zennium electrochemical workstation (Zahner, Germany) using a threeelectrode mode, with an anode acting as a working electrode, an $\mathrm{Ag} / \mathrm{AgCl}$ electrode $(+0.198 \mathrm{~V} v s$. SHE $)$ as a reference electrode, and a cathode as a counter electrode, respectively. During the measurement, the reference electrode was inserted in the anode chamber. Under turnover conditions, CV tests were conducted at a scan rate of $1 \mathrm{mV} \mathrm{s}^{-1}$ with the potential ranging from $-0.6 \mathrm{~V}$ to $+0.0 \mathrm{~V} v s$. $\mathrm{Ag} / \mathrm{AgCl}$. Under non-turnover conditions, $\mathrm{CV}$ tests were performed with scan rates increasing from $1 \mathrm{mV} \mathrm{s}^{-1}$ to $1 \mathrm{~V} \mathrm{~s}^{-1}$ and potential ranging from $-0.6 \mathrm{~V}$ to $+0.1 \mathrm{~V} \mathrm{vs.} \mathrm{Ag} / \mathrm{AgCl}$. EIS analysis was conducted at an external resistance of $1000 \Omega$ with frequency ranging from $100 \mathrm{kHz}$ to $10 \mathrm{mHz}$ and sinusoidal perturbation being $10 \mathrm{mV}$ amplitude.

Cell voltages of the MFCs were recorded every twenty $s$ by a data acquisition system (Agilent 34970A, The Netherlands). The power density curves were obtained by using a variable resistance box adjusting from 5 to $2500 \Omega$. The power densities $(P)$ of the MFCs were calculated according to eqn: $P=U I / A$, where $A$ is the projected the surface area of cathode, and $I$ and $U$ stand for current and cell voltage, respectively.

\section{Results and discussion}

\subsection{Surface characteristics of the used carbon-brush anodes}

After a $90 \mathrm{~h}$ inoculation, the four MFCs exhibited a similar steady voltage output. For clarity's sake, only one representative MFC start-up is shown in Fig. S1. $\uparrow$ The MFC showed a lag time of about $35 \mathrm{~h}$ and a stable voltage of $0.37 \mathrm{~V}$. Fig. 1 displays the surface morphology of mature anode samples dealt with different treatments. Since air drying was used, the entire anode surface was covered by the microorganism (Fig. 1a). As shown in Fig. 1d, a thin and compact biofilm was formed on each carbon fiber surface. Notably, the carbonization-treated anode exhibited much rougher surface and more agglomeration than the original carbon-brush anode. From high magnification observations in Fig. 1e, agglomeration particles were tightly attached to anode surface because of carbonization treatment. The Energy-Dispersive X-ray Spectroscopy (EDS) results of those 


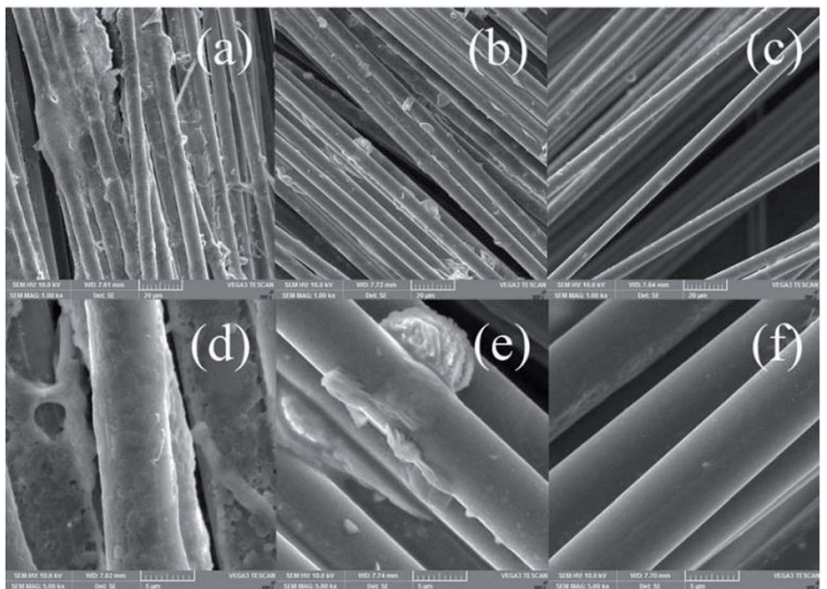

Fig. 1 SEM images of the mature carbon-brush anode treated by air drying (a), carbonization (b), alkaline soaking (c) and higher magnification of $a(d), b(e), c(f)$.

particles further showed that C (80.5 wt\%), O (18.4 wt\%) and slight amount of $\mathrm{P}(0.7 \mathrm{wt} \%), \mathrm{Na}(0.3 \mathrm{wt} \%)$ and $\mathrm{K}(0.1 \mathrm{wt} \%)$ were detected (Fig. $\mathrm{S} 2 \uparrow$ ). It has been reported that the protein and carbohydrate components of biomass is prone to convert to a mixture of char and mineral salts during high-temperature carbonization at $900{ }^{\circ} \mathrm{C}$, indicating that the attached agglomeration probably corresponds to char and mineral salts..$^{19,22,23}$ However, after alkaline treatment, no microbes were observed on the smooth anode surface. This is because extreme alkaline conditions would lead to irreversible biofilm degradation and then biofilm detachment from the electrode surface. ${ }^{24,25}$

XPS measurements were conducted to investigate chemical compositional information of the used carbon-brush anodes with different treatments. The EDS spectrum of the original carbon-brush anode (MFC-CB) demonstrated the presence of C and $\mathrm{O}$. As shown in Fig. S4a-c, $\dagger$ the high-resolution spectrum of C1s exhibited three main peaks at 284.6, 285.8 and $288.5 \mathrm{eV}$, which could be assigned to $\mathrm{C}-\mathrm{C}, \mathrm{C}-\mathrm{O}$, and $\mathrm{C}=\mathrm{O}$, respectively. Fig. S4d $\uparrow$ shows a high-resolution O1s scan, which indicated the existence of $\mathrm{C}=\mathrm{O}$ or $\mathrm{P}=\mathrm{O}(531.7 \mathrm{eV})$ and $\mathrm{C}-\mathrm{O}-\mathrm{C}(533.1 \mathrm{eV})$ bonds in MFC-CB anode. The high-resolution O1s patterns of MFC-C and MFC-A anodes revealed a new C-OH (532.8 eV) bond (cf. Fig. S4e and $\mathrm{f}_{\dagger} \dagger$ ). These data suggest that, compared with the original carbon-brush, both carbonization- and alkalinetreatments increase the number of carboxylic acid groups. In addition, the P2p spectrum of the MFC-C anode showed a peak at $133.3 \mathrm{eV}$ associated with $\mathrm{P}=\mathrm{O}$ bond, confirming phosphate functional groups on electrode surface (Fig. S4g†).

\subsection{MFC restart-up and performance}

The start-up processes of the three treated MFCs are shown in Fig. 2. Obviously, the different treatments for the used anodes significantly affected the MFC start-up. The lag time of the three treated MFCs was shorter than that of MFC-CB (thirty-five h). Interestingly, MFC-D showed the shortest lag time of fifteen $h$ among all the treated MFCs. Because of the formation of

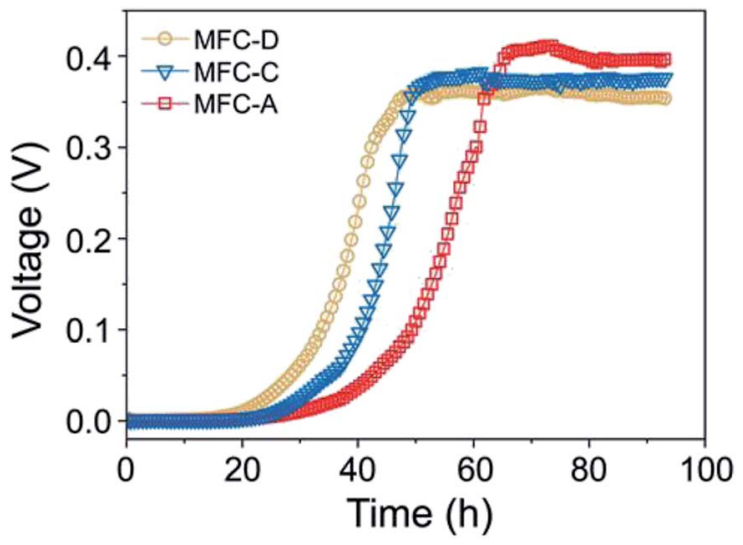

Fig. 2 Voltage evolution of MFC equipped with the used anode treated by different methods during restart-up.

agglomeration by carbonization, the anode surface of MFC-C can provide more attaching sites for biofilm development and thus reduce the lag time (about twenty-five $h$ ). The carbon-brush anode soaking in alkaline solution (MFC-A) may increase the affinity of microbes, and the lag time decreased to $30 \mathrm{~h}$. Furthermore, after ninety $\mathrm{h}$ inoculation, the cell voltages reached a steady state. Notably, MFC-A exhibited a high voltage output, while MFC-D and MFC-C showed a low voltage output in comparison with MFC-CB.

Fig. 3 displays the power density curves of the three treated MFCs and the control sample MFC-CB. The discrepant recovery degree was observed in these MFCs processed by different treatments. The maximum power densities of MFC-D (1.04 \pm $\left.0.03 \mathrm{~W} \mathrm{~m}^{-2}\right)$, MFC-C $\left(1.21 \pm 0.01 \mathrm{~W} \mathrm{~m}^{-2}\right)$ and MFC-A $(1.42 \pm$ $0.02 \mathrm{~W} \mathrm{~m}^{-2}$ ) were restored to $\sim 85 \%, 99 \%$ and $116 \%$ of MFC-CB $\left(1.22 \pm 0.01 \mathrm{~W} \mathrm{~m}^{-2}\right)$, respectively. The maximum current densities of MFC-D $\left(3.66 \pm 0.08 \mathrm{~A} \mathrm{~m}^{-2}\right)$, MFC-C $(4.36 \pm 0.07 \mathrm{~A}$ $\left.\mathrm{m}^{-2}\right)$ and MFC-A $\left(7.62 \pm 0.44 \mathrm{~A} \mathrm{~m}^{-2}\right)$ were restored to $\sim 59 \%$, $71 \%$ and $123 \%$ of MFC-CB $\left(6.17 \pm 0.22 \mathrm{~A} \mathrm{~m}^{-2}\right)$, respectively. In terms of the recovery degree of both maximum power and current densities, soaking the used anodes in alkaline solution is beneficial for the performance restoration of MFC.

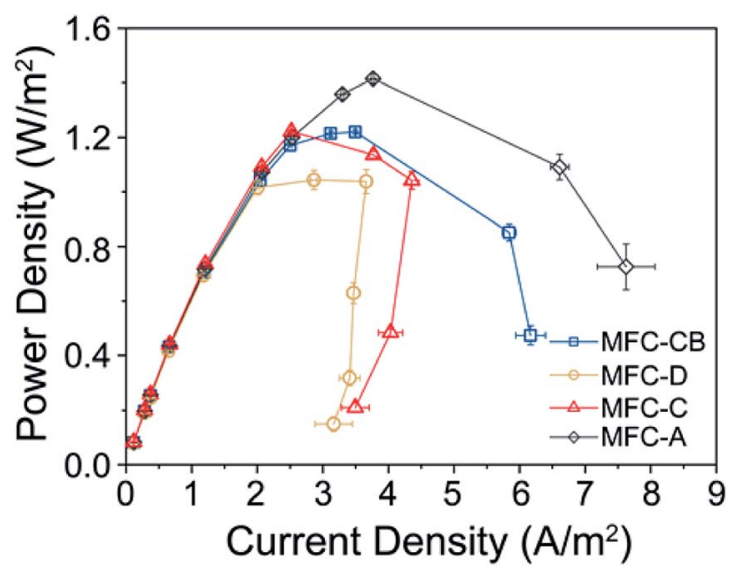

Fig. 3 Power density curves of MFCs with different anodes. 


\subsection{Cyclic voltammetry analyses of anodic biofilm}

$\mathrm{CV}$ tests were carried out to evaluate the bio-electrocatalytic activity of biofilm on the anode surface. Fig. 4a displays CVs of biofilm under turnover condition. The CV curves of the anodic biofilm exhibited similar sigmoidal catalytic waves but different levels of bio-catalytic current, which is regarded as an indicator of the bio-electrocatalytic activity of biofilm. Characterized by voltammograms in Fig. 4a, the peak current values of the MFC anodes increased in the following order: MFC-D < MFC-C < MFC-CB < MFC-A. Therefore, the electrochemical activity of the biofilm was enhanced after the used anode was treated by alkaline soaking, whereas the air drying and carbonization treatment for the used anode showed a decreased performance compared to the anode biofilm of MFC-CB.

With acetate serving as electron donors, the typical sigmoidal $\mathrm{CV}$ resulted from multiple turnovers of each redox system. ${ }^{26,27}$ The CVs were performed on the anodic biofilm of MFCs under nonturnover condition at a slow scan rate of $1 \mathrm{mV} \mathrm{s}^{-1}$ to confirm dominant individual redox system. As illustrated in Fig. 4b, all MFC anodes revealed several similar reversible peaks in the absence of substrate. Among them, redox system E (marked by arrow) was the dominance of electricity generation regarding the height of peak currents. It has been reported that the redox system $\mathrm{E}$ with a formal potential of $-0.17 \mathrm{~V} v$ s. SHE may belong to OmcB (outer membrane c-type cytochrome B), which mediates the electron transfer of bacteria to solid electrodes by direct electron transfer. ${ }^{28,29}$ Moreover, the formal potential $(-0.17 \mathrm{~V})$ of the redox system $\mathrm{E}$ was consistent with the acetate-oxidation formal potential of biofilm under turnover condition, implying that the bioelectrocatalytic activity of all anodes predominantly depends on the electron transfer capability of OmcB. Therefore, the CV results under both turnover and non-turnover conditions illuminated that the bio-electrocatalytic activity of the biofilm changed using different methods to treat the used anode, whereas the anodic electron transfer mechanism of all MFCs was unchanged, corresponding to the direct electron transfer by OmcB.

\subsection{Electrochemical kinetics of anodic biofilm}

Although electron transfer path of all MFC anodes was identical, their electrochemical kinetics was diverged according to the $\mathrm{CV}$ analysis with different scan rates. As seen in Fig. $5 \mathrm{a}-\mathrm{d}$, increasing the CV scan rate $(v)$ from 10 to $80 \mathrm{mV} \mathrm{s}^{-1}$, there was a good linear correlation between the scan rates and peak currents of the anodic biofilm for all MFCs except MFC-D (inset in Fig. 5a-d). The linear dependence of the peak heights on the scan rates indicates typical surface-controlled electrochemical processes for anodes. In this case, the current generation of anodes is limited by the slow interfacial electron transfer between the bacterial outer membrane proteins and the anode surface. Considering $\mathrm{OmcB}$ mentioned above as the final electron carrier of the redox proteins in MFC anodes, it can be concluded that the performance of MFC-CB, MFC-C and MFC-A strongly depends on the electron transfer properties between OmcB and anode surfaces. The dependency of peak currents on scan rates $(v)$ and their square roots $\left(v^{1 / 2}\right)$ was analyzed in Fig. 5e and $\mathrm{f}$ to further investigate the electron transfer of the MFC-D anode. The peak current was proportional to $\mathrm{v}$ (slow-scan rate range: $1-10 \mathrm{mV} \mathrm{s}^{-1}$ ) while it was linear to $v^{1 / 2}$ (high-scan rate range: $10-100 \mathrm{mV} \mathrm{s}^{-1}$ ), implying typical diffusion-controlled electrochemical processes for the MFC-D anode. It has been reported that diffusion-control results from the confined diffusion of charge-compensating ions in the biofilm in the absence of redox mediators. ${ }^{30}$ This indicates that the MFC-D performance is limited by the diffusion of chargecompensating ions within the biofilm (such as acetate substrate and proton product) at high current densities. The existence of the diffusion resistance inside the biofilm of MFCD probably results from the hindrance of parts of dead bacteria on the anode surface, which was formed via air drying treatment for the mature biofilm. This indicates that the shortest start-up times of MFC-D is partly caused by bacterial resurgence rather than the fresh biofilm formation.

As shown in Fig. 6, insights were performed to further investigate the influence of the treatments for the used anodes on the electrochemical kinetics of biofilm. On the basis of the redox peak potential of the MFC anodes with scan rates ranging from 1 to $100 \mathrm{mV} \mathrm{s}^{-1}$, the curves of $E_{\mathrm{pa}}-E_{\mathrm{a}}^{0^{\prime}}$ versus $\ln (v)\left(E_{\mathrm{pa}}\right.$ is the anodic peak potential and $E_{\mathrm{a}}^{0^{\prime}}$ is the anodic formal potential) was plotted in Fig. 6a to analyze the electron transfer rate constant from the following equation: ${ }^{31}$

$$
E_{\mathrm{pa}}=E_{\mathrm{a}}^{0^{\prime}}-\left[\frac{R T}{(1-\alpha) n F}\right] \ln \left[\frac{(1-\alpha) n F \nu}{R T \kappa_{\mathrm{app}}}\right]
$$

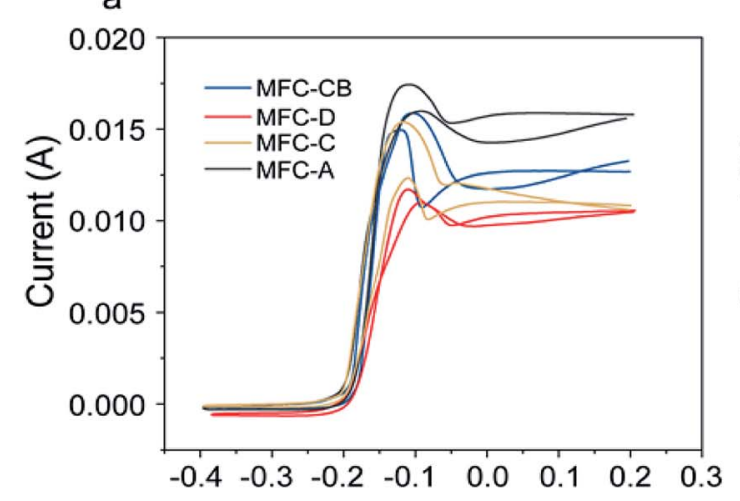

b

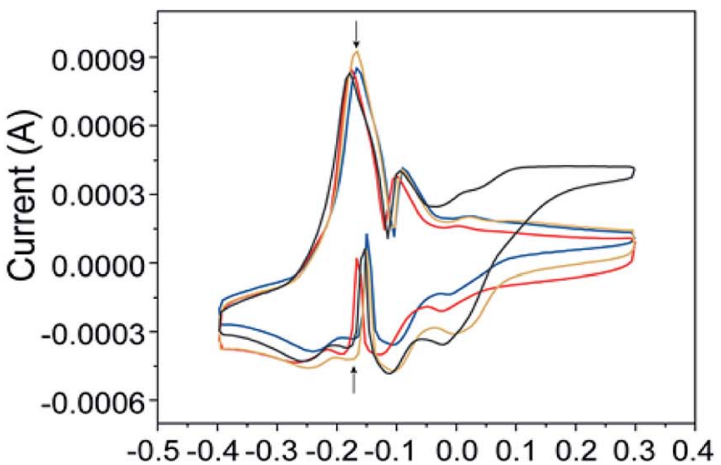

Fig. $4 \mathrm{CV}$ responses on anodic biofilms of MFC-CB, -D, $-\mathrm{C}$ and $-\mathrm{A}$ at a scan rate of $1 \mathrm{mV} \mathrm{s} \mathrm{s}^{-1}$ under turnover (a) and non-turnover (b) condition. 
a

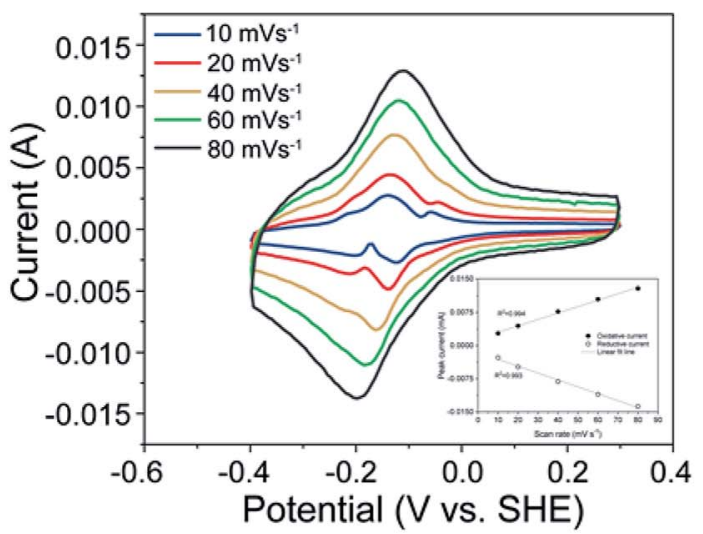

C
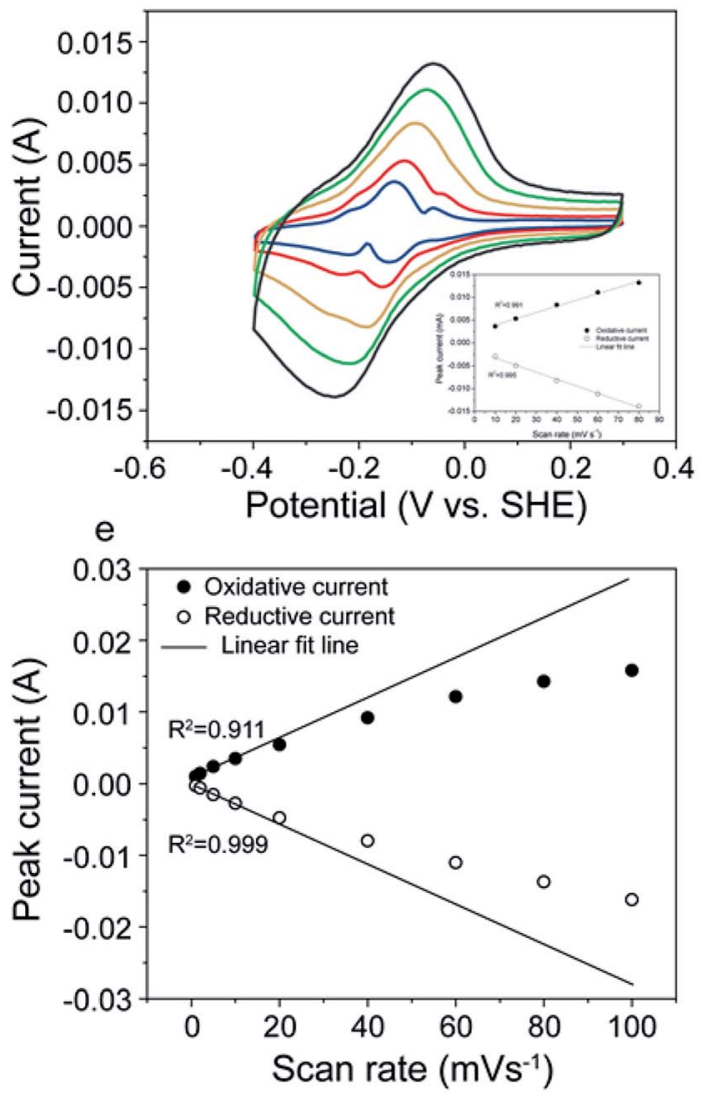

b

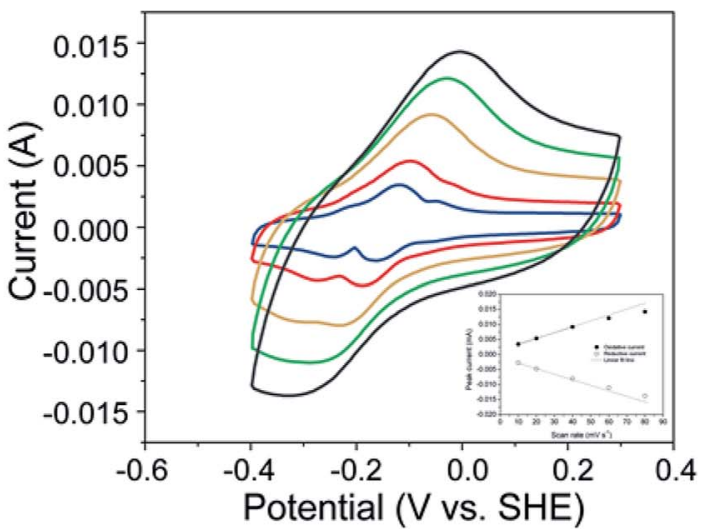

d
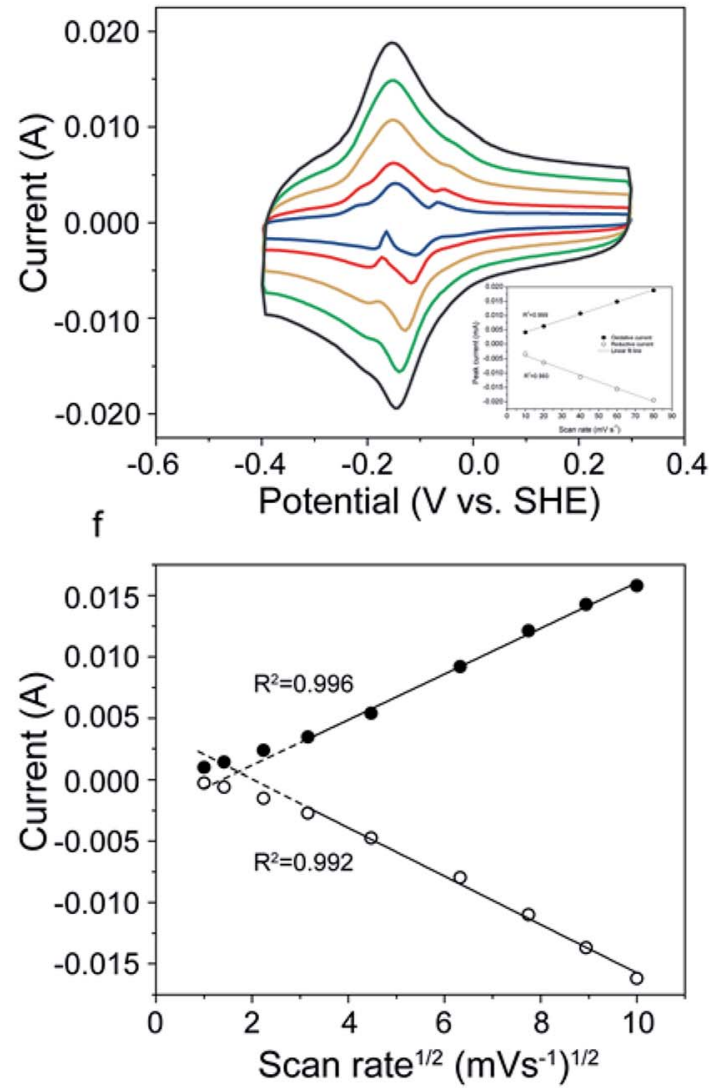

Fig. 5 CVs of anodic biofilms under non-turnover condition with different scan rate. The biofilm was formed on original anode (a) and the used anode treated by air drying (b), carbonization (c), alkaline soaking (d). Plot of peak currents of the air drying-treated anode as a function of scan rates (e) and square root of scan rate (f).

where $R$ is the ideal gas constant, $T$ stands for the temperature in kelvin degree, $F$ is Faraday constant, $n$ represents the electron transfer number, $\nu$ is the scan rate, $\alpha$ is the charge transfer coefficient and $\kappa_{\text {app }}$ is the apparent electron transfer rate constant. When the separation of anodic to cathodic peak potentials was larger than $200 \mathrm{mV} / n$, the $\kappa_{\text {app }}$ values for the redox system $\mathrm{E}$ could be gained according to eqn (1) and are summarized in Table 1 . As shown in Table 1 , the $\kappa_{\text {app }}$ values of the anodes of MFC-CB, MFC-D, MFC-C and MFC-A were 5.59, $1.20,1.27$ and $27.31 / \mathrm{s}$, respectively. A high $\kappa_{\text {app }}$ of the alkalinetreated anode implies a fast electron transfer rate, while a decreased $\kappa_{\text {app }}$ value suggests hindered electron transfer at air drying- and carbonization-treated anodes.

In addition, EIS was carried out to evaluate the internal resistances of the MFC anodes. From Nyquist plot in Fig. 6b, the impedance spectra of four MFC anodes was successfully fitted with the equivalent circuit as described previously, in which $R_{1}$ is the resistance of oxidation or reduction processes of metal salts and $R_{\text {ct }}$ represents the interfacial charge-transfer resistance. $^{32}$ The detailed resistances of the MFC anodes are summarized in Table 1. The differences in the charge transfer resistances were observed. The $R_{\mathrm{ct}}$ values of the anode of MFC- 
a

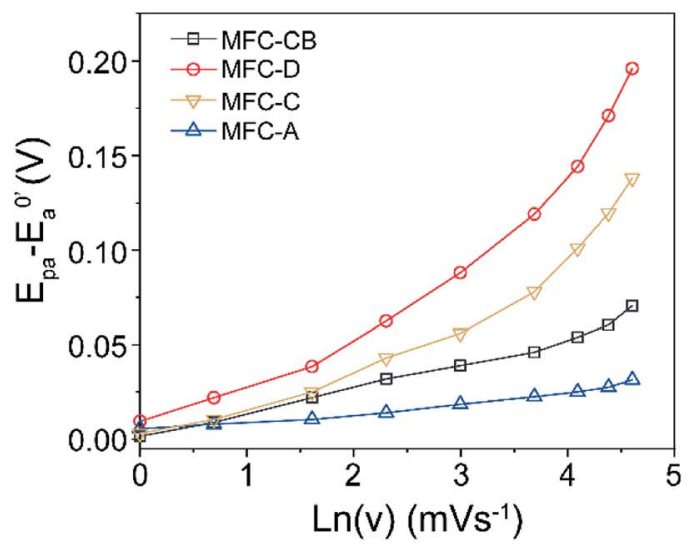

b

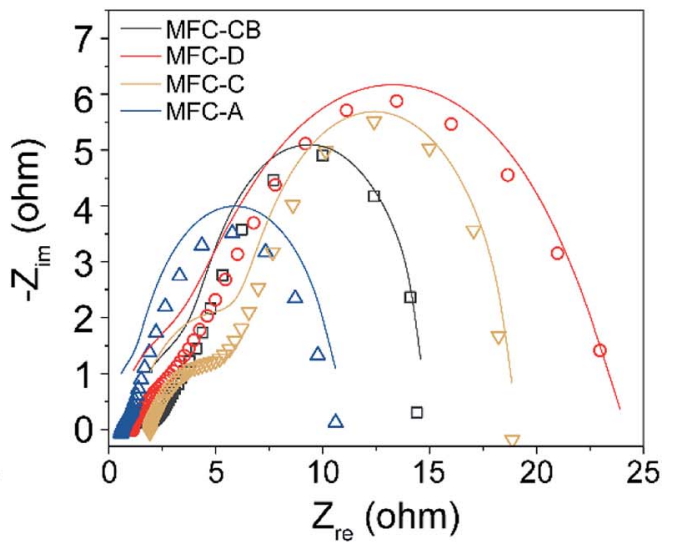

Fig. 6 Electrochemical kinetics characterizations on anodic biofilms of MFC-CB, -D, -C and -A. Anodic peak potentials as a function of the Napierian logarithm of CV scan rates (a) and Nyquist plots of the anodic biofilms (b).

Table 1 Summary of $P_{\text {max }}, I_{\text {max }}$, electron transfer rate constant $\kappa_{\text {app }}$ and charge-transfer resistance $R_{\mathrm{ct}}$ on anodic biofilms of MFC-CB, -D, $-C$ and $-A$

\begin{tabular}{lllrr}
\hline MFC samples & $P_{\max }\left(\mathrm{W} \mathrm{m}^{-2}\right)$ & $I_{\max }\left(\mathrm{A} \mathrm{m}^{-2}\right)$ & $\kappa_{\text {app }}(\mathrm{s})$ & $R_{\mathrm{ct}}(\Omega)$ \\
\hline MFC-CB & $1.22 \pm 0.01$ & $6.17 \pm 0.22$ & 5.59 & 9.9 \\
MFC-D & $1.04 \pm 0.03$ & $3.66 \pm 0.08$ & 1.20 & 18.8 \\
MFC-C & $1.21 \pm 0.01$ & $4.36 \pm 0.07$ & 1.27 & 11.6 \\
MFC-A & $1.42 \pm 0.02$ & $7.62 \pm 0.44$ & 27.31 & 8.0 \\
\hline
\end{tabular}

CB, MFC-D, MFC-C and MFC-A were 9.9, 18.8, 11.6 and 8.0 $\Omega$, respectively. In general, a low charge transfer resistance represented a fast electron transfer rate. ${ }^{32,33}$ Thus, the lowest charge transfer resistance of the MFC-A anode suggests the fastest electron transfer rate among the four cases. The EIS result was consistent with the aforementioned electron transfer rate result. The above results demonstrate that compared with the original carbon-brush anode, the air drying, and carbonization treatments of the used anodes are detrimental to the electron transfer from bacteria to electrodes. However, the reason for decreasing electron-transfer rate was discrepant. In the case of air drying treatment, parts of dead bacteria on the anode surface might inhibit the metabolite diffusion from biofilm to solution and then the aggregate metabolite within biofilm caused an unfavorable microenvironment (i.e. low $\mathrm{pH}$ ) for bacterial electricity generation, thus leading to a low electrontransfer rate. By comparison, after carbonization, the electrode surface might be connected with active functional group and partly covered by mineral salts (such as sodium/potassium phosphate) produced by the pyrolysis of biofilm growing in a $\mathrm{Na}^{+} / \mathrm{K}^{+}$-rich phosphate buffer solution. ${ }^{19,22}$ In this case, on the anode surface, the weakly conductive materials resulted from phosphate coverage is probably responsible for the decrease in the electrochemical activity area and the conductive capability of the electrode, finally leading to the reduction of the electrontransfer rate. On the other hand, the alkaline treatment for the used anode accelerated the electron transfer rate between the regenerative biofilm and the anode surface. XPS results mentioned above demonstrate that alkaline treatment could increase the numbers of carboxylic acid groups on the carbonbrush surface. ${ }^{34,35}$ Between carboxyl groups and bacterial cytochromes, the hydrogen bonding that facilitated the electron transfer is prone to be formed..$^{36-38}$ Thus, the alkaline-treated anode showed the fastest electron-transfer from the electrode surface to OmcB among all the cases.

In conclusion, the performance of the MFC treated by air drying was limited by the diffusion of substrate through biofilm. A slow diffusion of products might decrease the electrochemical activity of biofilm. Thus, both the slow diffusion rate and the low electrochemical activity probably resulted in the low-recovery power generation of MFC-D. However, considering that the performance of MFC-CB, MFC-C and MFC-A mainly depended on the electron transfer between anodes and $\mathrm{OmcB}$, the surface property of the electrode had significant effects. The carbonization treatment of the used anode resulted in the decrease of the electrochemical activity of the anode and thus decreased the power production of MFC-C at high current densities. On the contrary, alkaline treatment achieved a complete removal of the aging biofilm and enhanced the electrochemical activity of the regenerative biofilm, making this treatment a simple and effective method for the high-recovery of MFC performance in practical application.

\section{Conclusions}

In this work, the performance recovery of MFCs equipped with the used anodes treated by different methods was investigated. The proposed alkaline treatment for the used anode induces the increase in the electrochemical activity and the kinetic feature of biofilm, leading to the high-recovery of MFC performance. However, the used anode with air drying treatment cannot be reused to generate power in MFC. This is because the limited diffusion of substrate and product within biofilm decreases MFC performance recovery. The carbonization treatment of the used anode caused the weak electrochemical activity of biofilm and the reduction of MFC performance recovery. 


\section{Conflicts of interest}

There are no conflicts to declare.

\section{Acknowledgements}

This work was supported by the National Natural Science Foundation of China [grant number 51706030]; the Fundamental Research Funds for the Central Universities [grant number DUT18JC11] and the China Postdoctoral Science Foundation [grant number 2018T110218].

\section{References}

1 J. Zhang, J. Li, D. Ye, X. Zhu, Q. Liao and B. Zhang, J. Power Sources, 2014, 272, 277-282.

2 Q. Liao, J. Zhang, J. Li, D. Ye, X. Zhu and B. Zhang, Biosens. Bioelectron., 2015, 63, 558-561.

3 Y. Feng, Q. Yang, X. Wang and B. E. Logan, J. Power Sources, 2010, 195, 1841-1844.

4 F. Zhao, N. Rahunen, J. R. Varcoe, A. Chandra, C. AvignoneRossa, A. E. Thumser and R. C. Slade, Environ. Sci. Technol., 2008, 42, 4971-4976.

5 L. Li, R. Chen, X. Zhu, Q. Liao, H. Wang, L. An and M. Zhang, J. Catal., 2016, 344, 411-419.

6 A. J. Hutchinson, J. C. Tokash and B. E. Logan, J. Power Sources, 2011, 196, 9213-9219.

7 C. Santoro, I. Ieropoulos, J. Greenman, P. Cristiani, T. Vadas, A. Mackay and B. Li, J. Power Sources, 2013, 238, 190-196.

8 B. Logan, S. Cheng, V. Watson and G. Estadt, Environ. Sci. Technol., 2007, 41, 3341-3346.

9 Y. Dong, Y. Qu, W. He, Y. Du, J. Liu, X. Han and Y. Feng, Bioresour. Technol., 2015, 195, 66-72.

10 L. Huang and B. E. Logan, Appl. Microbiol. Biotechnol., 2008, 80, 349-355.

11 Y. Ahn and B. E. Logan, Appl. Microbiol. Biotechnol., 2013, 97, 409-416.

12 L. Zhuang, Y. Yuan, Y. Wang and S. Zhou, Bioresour. Technol., 2012, 123, 406-412.

13 F. Zhang, Z. Ge, J. Grimaud, J. Hurst and Z. He, Bioresour. Technol., 2013, 134, 251-256.

14 M. Rimboud, A. Bergel and B. Erable, Bioelectrochemistry, 2016, 110, 46-51.

15 Y. Yang, D. Ye, Q. Liao, P. Zhang, X. Zhu, J. Li and Q. Fu, Biosens. Bioelectron., 2016, 79, 406-410.

16 C.-H. Wu and C.-W. Lin, J. Taiwan Inst. Chem. Eng., 2016, 68, 332-337.
17 B. Jiang, B. Dou, K. Wang, C. Zhang, Y. Song, H. Chen and Y. Xu, Chem. Eng. J., 2016, 298, 96-106.

18 Z. Shuping, W. Yulong, Y. Mingde, L. Chun and T. Junmao, Bioresour. Technol., 2010, 101, 359-365.

19 A. Ross, J. Jones, M. Kubacki and T. Bridgeman, Bioresour. Technol., 2008, 99, 6494-6504.

20 C. Faille, T. Bénézech, W. Blel, A. Ronse, G. Ronse, M. Clarisse and C. Slomianny, Food Microbiol., 2013, 33, 149-157.

21 H. Cox and M. Deshusses, Water Res., 1999, 33, 2383-2391.

22 Y. Zhu, C. W. Kwong, P. J. van Eyk, R. de Nys, D. Wang and P. J. Ashman, Energy Fuels, 2015, 29, 5047-5055.

23 B. Jiang, C. Zhang, K. Wang, B. Dou, Y. Song, H. Chen and Y. Xu, Appl. Therm. Eng., 2016, 109, 99-108.

24 S. A. Patil, F. Harnisch, C. Koch, T. Hübschmann, I. Fetzer, A. A. Carmona-Martínez, S. Müller and U. Schröder, Bioresour. Technol., 2011, 102, 9683-9690.

25 L. Li, D. Tang, Y. Song, B. Jiang and Q. Zhang, Energy, 2018, 149, 937-943.

26 E. Marsili, J. Sun and D. R. Bond, Electroanalysis, 2010, 22, 865-874.

27 K. Fricke, F. Harnisch and U. Schröder, Energy Environ. Sci., 2008, 1, 144-147.

28 K. P. Katuri, P. Kavanagh, S. Rengaraj and D. Leech, Chem. Commun., 2010, 46, 4758-4760.

29 Q. Fu, H. Kobayashi, H. Kawaguchi, T. Wakayama, H. Maeda and K. Sato, Environ. Sci. Technol., 2013, 47, 12583-12590.

30 H. Richter, K. P. Nevin, H. Jia, D. A. Lowy, D. R. Lovley and L. M. Tender, Energy Environ. Sci., 2009, 2, 506-516.

31 Y. Yuan, B. Zhao, S. Zhou, S. Zhong and L. Zhuang, Bioresour. Technol., 2011, 102, 6887-6891.

32 J. Zhang, J. Li, D. Ye, X. Zhu, Q. Liao and B. Zhang, Int. J. Hydrogen Energy, 2014, 39, 19148-19155.

33 J. Zheng, C. Cheng, J. Zhang and X. Wu, Int. J. Hydrogen Energy, 2016, 41, 23156-23163.

34 Z. Chen, P. Lu, H. Zhu, B. Du, T. Xie, W. Wang and M. Xu, Electrochim. Acta, 2013, 102, 44-50.

35 B. Jiang, B. Dou, Y. Song, C. Zhang, B. Du, H. Chen, C. Wang and Y. Xu, Chem. Eng. J., 2015, 280, 459-467.

36 X. Tang, K. Guo, H. Li, Z. Du and J. Tian, Bioresour. Technol., 2011, 102, 3558-3560.

37 L. Li, Y. Song, B. Jiang, K. Wang and Q. Zhang, Energy, 2017, 131, 58-66.

38 B. Jiang, B. Dou, K. Wang, Y. Song, H. Chen, C. Zhang, Y. Xu and M. Li, Fuel, 2016, 183, 170-176. 